\title{
CUTOFF VALUE OF KI-67 BIOMARKER AS PROGNOSTIC MARKER IN FEMALE BREAST CANCER
}

(Retrospective Study)

By
Nabil Desoky El-Bahr, Hesham Abbas Al-Abady and Ahmed Yousry Al- Agmawy

Radiation Oncology Department, Faculty of Medicine, Al-Azhar University, Cairo, Egypt

Corresponding author: Nabil Desoky El-Bahr

Mobile: 01002321014, E-mail: nabil.elbahr3@gmail.com

\begin{abstract}
Background: Cancer breast (BC) is the commonest worldwide malignancy in females. KI-67 one of prognostic biomarker in breast cancer.

Objective: Assessing KI-67\% expression in relationship with disease free survival (DFS), over-all survival (OS) and various clinic-pathological parameters of the disease (age, menopausal status, tumor size, nodal status, histological type/ grade, Estrogen receptors Progesterone receptors (ER, PR) status and Human Epidermal Growth Factor Receptor (HER2neu) status.

Patients and Methods: This study included 115 female breast cancer patients were done KI-67\% biomarker. Our cases at Clinical Oncology Department, Al-Hussein University Hospital during the period between January 2014 and December 2017.

Results: Cutoff value of KI-67\% was significance (P-value < 0.01) with (ER, PR and HER2neu), significance $(\mathrm{P}$-value $<0.05)$ with DFS and insignificance $(\mathrm{P}$-value $>0.05)$ with OS, age, menopausal status, tumor size, nodal status, histological type/ grade).

Conclusion: Patients with high KI-67\% showed significantly poorer prognosis than those with low KI-67\%. This may show that KI-67\% was the most robust independent prognostic factor in multivariate prognostic analysis, despite having very strong correlations with other biomarkers such as hormone receptor status (ER \& PR) and HER2neu. KI-67\% might be helpful in identifying patients who have a favorable diagnosis and in preventing unnecessary treatment for these women.
\end{abstract}

Keywords: KI-67\%, DFS, OS, ER, PR and Her2neu.

\section{INTRODUCTION}

$\mathrm{BC}$ is the most frequently diagnosed cancer among women worldwide about $25 \%$ of all new cancer diagnosis in women globally and 29\% in Egyptian's females (Jemal et al., 2011).
It is well recognized that $\mathrm{BC}$ is a heterogeneous disease, and that the biological nature of the disease and clinical outcome are closely interlinked (Brandt et al., 2017).

Discussion of malignant breast patients is now carefully using a variety of 
prognostic and predictive factors. Rating of these factors has become a requisite section of the pathologists mapping and practice, and only with this information available can the clinical team select the most appropriate treatment for the individual patient (Giuliano, et al., 2017).

However, a few of these factors found their way into routine clinical application as established prognostic tools. These primarily include: Nodal status, neoplasm size, histological type/ grade, (ER, PR) status, (HER2neu) status and KI-67 proliferation index (Gonzalez-Angulo et al., 2011).

Several other investigational ingredients have been proposed for prognostic and predictive determination including, for instance: proliferative markers, cell cycle regulatory proteins, bone marrow micro metastases, circulating tumor cells and multi-gene assays. None of these ingredients, however, made its way into clinical routine practice (Schmidt et al., 2012).

Prognostic and predictive breast cancer markers are imperative in predicting patient survival and relapse, as well as in deciding their treatment protocols. Although a multitude of supposed prognostic and predictive markers have been examined, only routine histopathological and immunohistochemically markers have proven useful (Taneja et al., 2014).

Only MAI and KI-67 labelling index appear too applied in routine use. KI-67 has also become established in medicinebased practice. KI-67 is present in all phases of the cell cycle, with its maximum during mitosis. The percentage of cell that changed color positively for KI-67 IHC stain has been used as a measure of growth and spread as well as prediction of outcome in many trials (Pinto AC et al., 2011).

The present work aimed to assess KI$67 \%$ expression in relationship with disease free survival, over-all survival and various clinic-pathological parameters of the disease (age, menopausal status, tumor size, nodal status, histological type/ grade, Estrogen receptors Progesterone receptors (ER, PR) status and Her-2/Neu status).

\section{PATIENTS AND METHODS}

This were a retrospective study that included the 115 female patients with the diagnosis of $\mathrm{BC}$ registered at the archive of Clinical Oncology and Nuclear Medicine Department, Al-Hussein University Hospital during the period between January 2014 and December 2017. The patients were diagnosed of all stages of BC (Tis, T1, T2, T3, and T4), and all histological types (IDC, ILC, Mixed, Mucinous, Medullary carcinoma, and DCIS). All patients were subjected to an IHC examination for KI-67\% expression. All of patients were given one or more types of adjuvant or neoadjuvant chemotherapy, hormonal treatment and or radiotherapy following primary surgery.

\section{Statistical Methods:}

Data were collected, revised, coded and entered to the Statistical Package for the Social Science (IBM SPSS) version 23. The quantitative data were presented as mean, standard deviations and ranges when their distribution found parametric and median with inter-quartile range (IQR) when their distribution found non parametric. Also, qualitative variables were presented as number and 
percentages. The comparison between groups with qualitative data was done by using Chi-square test. The comparison between two groups with quantitative data and parametric distribution were done by using Independent t-test while for nonparametric data were done by using Mann-Whitney test. Kaplan Meier curve (Log Rank test) was used to assess the relation between KI67 and DFS and also OS of the studied cases the confidence interval was set to $95 \%$ and the margin of error accepted were set to $5 \%$. So, the pvalue was considered significant as the following: (P-value > 0.05: Non significant (NS), P-value < 0.05: Significant (S) and P-value < 0.01: Highly significant (HS).

\section{Ethical Approval:}

The current data were collected from patient's files from archive of Clinical Oncology Department, Al Hussein Hospital, and had been approved by the ethical committee, Faculty of Medicine, Al-Azhar University, Cairo, Egypt, before the start of this study.

\section{RESULTS}

The association between different clinic pathological parameters, including age menopausal status at diagnosis, tumor size, histological types, grade, nodal status ER, PR, her2neu status and type of surgery and KI-67 is show in Table (1).

The patients' age at diagnosis ranged from 30 to 76 years with a mean 45.41years and SD \pm 8.49 years. In the low KI- $67<20 \%$ patients' group, the median age at diagnosis was $46.58 \pm 9.01$ years compared with high KI-67>20\% patient group $44.40 \pm 7.96$ years. The difference between low and high KI-67 ratio as regard the age was statically nonsignificant $(\mathrm{P}=0.171)$ (Figure 1).

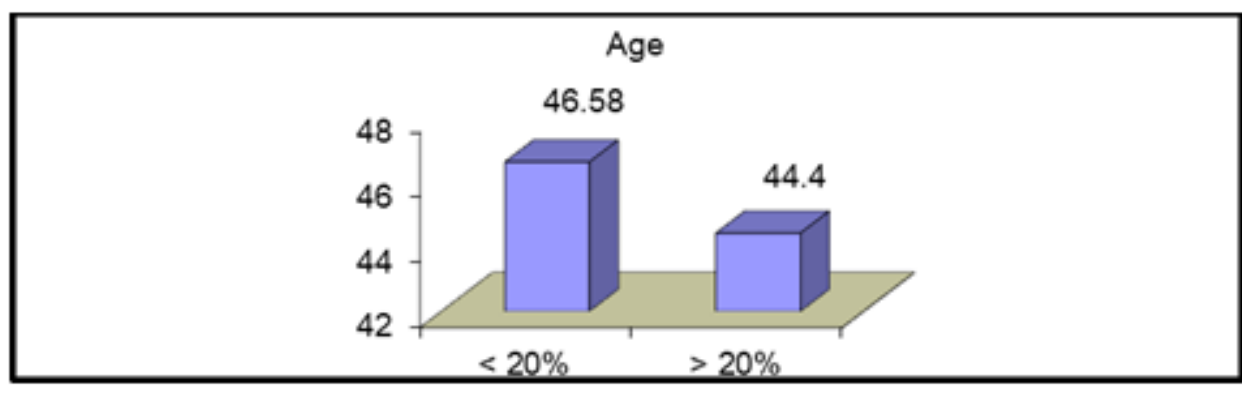

Figure (1): Relation between KI-67 percentage and mean age of our patients 45years

According to menopausal status of patients at diagnosis, there were no statistically significant differences in KI67 neither in premenopausal nor postmenopausal groups $(\mathrm{P}=0.677)$. In the KI-67 low group< $20 \%$, there were
$27(50.9 \%)$ premenopausal patients and 26(49.1\%) postmenopausal patients. While in the high KI-67 group $>20 \%$, there were $34(54.8 \%)$ premenopausal and $28(45.2 \%)$ postmenopausal patients (Figure 2). 


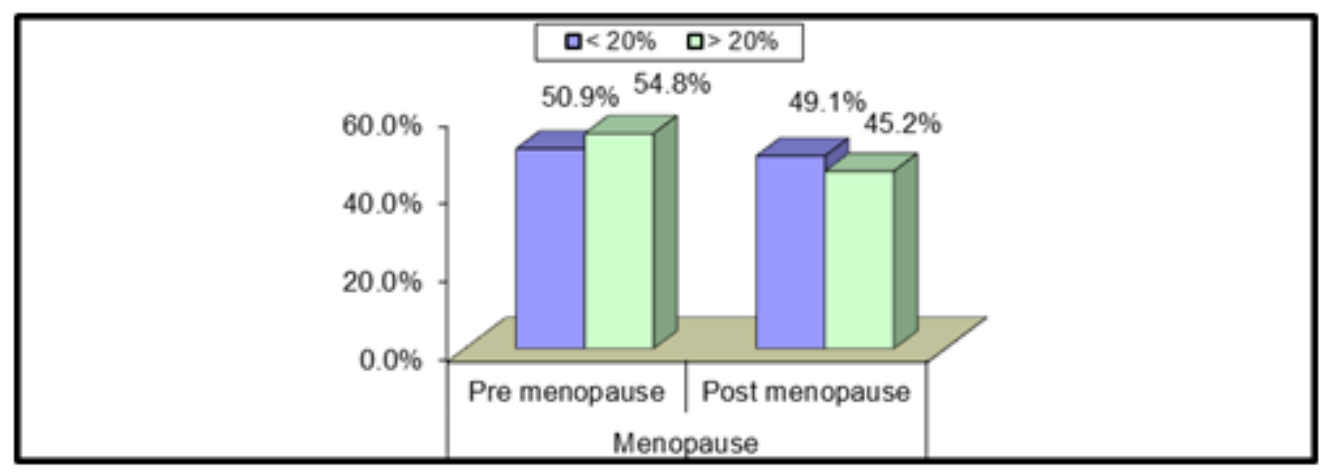

Figure (2): Relation between KI-67 percentage and menopausal status of our patients

All tumor histopathological types have no statistically significant difference for low and high KI-67( $\mathrm{P}=0.534)$. In low KI$67<20 \%$ \{IDC $47(88.7 \%)$, ILC $3(5.7 \%)$, mixed 0(0.0\%), Mucinous 1(1.9\%), DCIS $2(3.8 \%)$ and medullary carcinoma
$0(0.0 \%)\}$ and in high KI-67>20\% \{ IDC 56(90.3\%), ILC 3(4.8\%), Mixed 1(1.6\%), Mucinous 1(1.6\%), DCIS 0(0.0\%) and Medullary carcinoma 1(1.6\%)\} (Figure 3).

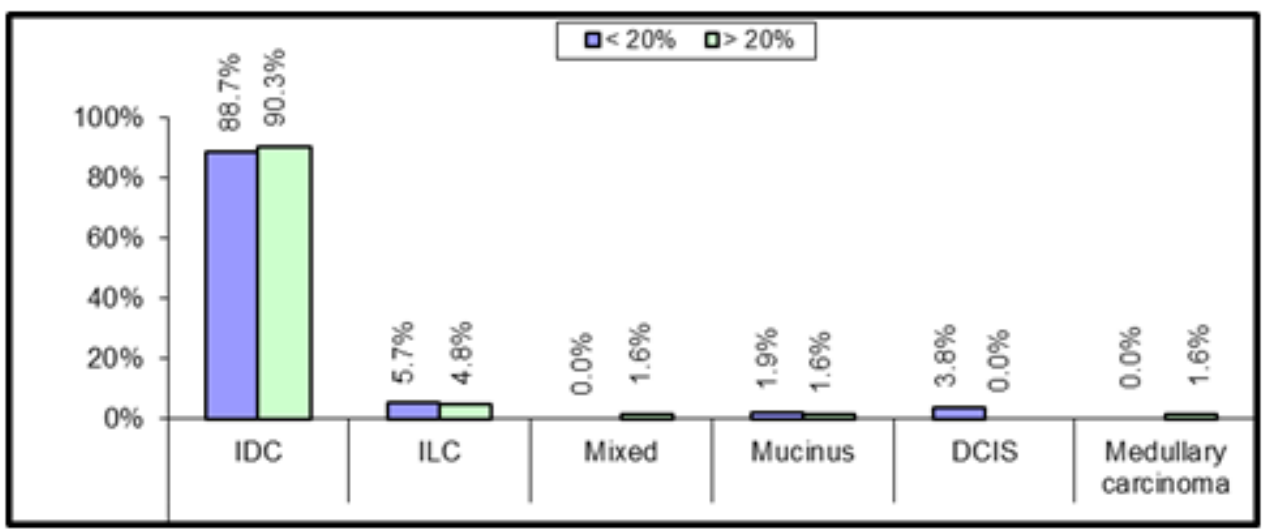

Figure (3): Relation between KI-67 percentage and pathological types of our patients

Difference size of $\mathrm{BC}$ has no statistically significance $(\mathrm{P}=0.382)$. In low KI-67<20\% [TIS 2(3.8\%), T1 8(15.1\%), T 2 29(54.7\%), T3 9(17.0\%) and T4 $5(9.4 \%)$ ] patients. In high KI-67>20\% [TIS $0(0.0 \%), \quad$ T1 $7(11.3 \%), \quad$ T2 $38(61.3 \%)$, T3 14(22.6\%) and T4 $3(4.8 \%)]$ patients.

The low KI-67 patient group $<20 \%$ contained $18(34.0 \%)$ patients with negative LNs, $17(32.1 \%)$ patients with
$\mathrm{N} 1,12(22.6 \%)$ patients with $\mathrm{N} 2$ and $6(11.3 \%)$ patients with N3. On the other hand, the high KI-67\% patient group $>20 \%$ contained $17(27.4 \%)$ patients with negative LNs, $20(32.3 \%)$ patients with $\mathrm{N} 1,15(24 \%)$ patients with $\mathrm{N} 2$ and $10(16.1 \%)$ patients with N3. Correlation analysis revealed no statistically significance between KI-67 expression and nodal status $(\mathrm{P}=0.824)$ (Figure 4). 


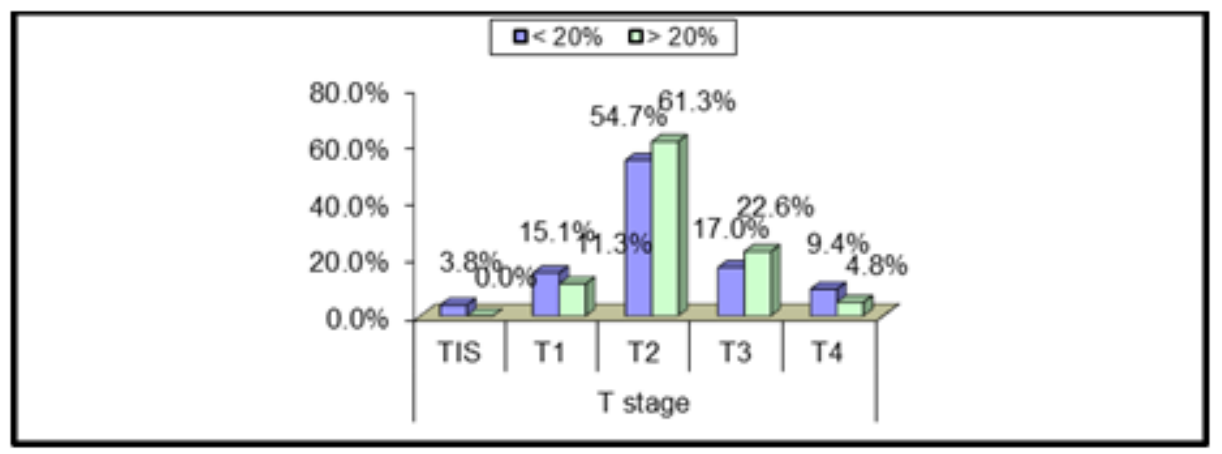

Figure (4): Relation between KI-67 percentage and tumor size staging of our patients

In the low KI-67 group $<20 \%$, there were $0(0.0 \%)$ patients with G1 tumors, $49(92.5 \%)$ patients with G2 tumors and $4(7.5 \%)$ patients with $\mathrm{G} 3$ tumors. While in the high KI-67 group $>20 \%$, there were $1(1.6 \%)$ patient with G1 tumors, 49
(78.0\%) patients with G2 tumors and 12(19.4\%) patients with G3 tumors. That is to say that there is no statistically significance between KI-67 expression and histological grade $(\mathrm{P}=0.115)$ (Figure 5).

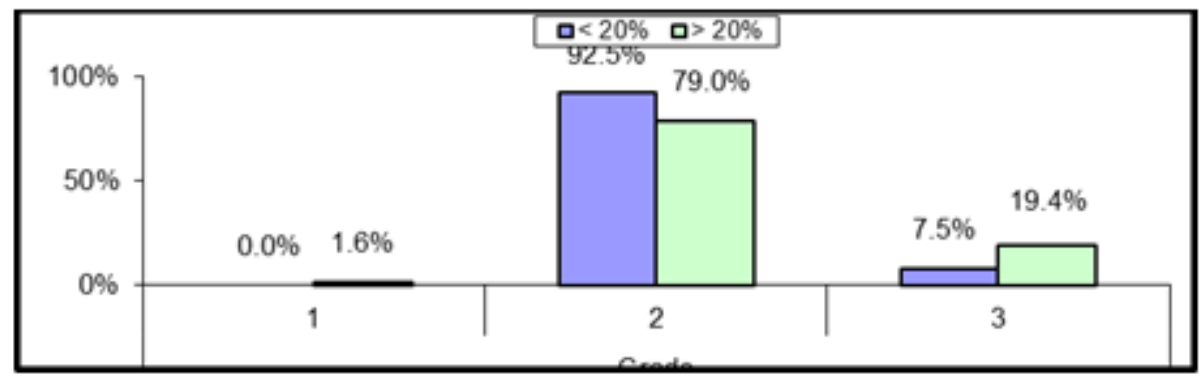

Figure (5): Relation between KI-67 percentage and tumor grading of our patients

As regard the impact of hormonal [ER] status on KI-67 expression, there is a high statistically significance in association between KI-67 expression and ER status $(\mathrm{P}=0.001)$. That is to say that KI-67 expressing breast cancer was frequently associated with negative ER tumors. In low KI-67 patients' group $<20 \%$ showed $2(3.8 \%)$ ER negative patients and 51(96.2\%) ER positive patients. In high KI-67 patients' group $>20 \%$ showed $16(25.8 \%)$ ER negative patients and 46(74.2\%) ER positive patients. Also as regard the association of [PR] hormonal status and KI-67 expression, there is also high statistically significance in association between KI-67 expression and PR status $(\mathrm{P}=0.001)$. That is to say that KI-67 expression breast cancer was frequently associated with negative PR tumors. In low KI-67 patients' group
$<20 \%$ showed $4(7.5 \%)$ PR negative patients and $49(92.2 \%)$ PR positive patients. In high KI-67 patients' group $>20 \%$ showed $21(33.9 \%)$ PR negative patients and $41(66.1 \%)$ PR positive patients. As regard the association between HER2/NEU status and KI-67 expression, in low KI-67 patient group $<20 \%$ showed 50(94.3\%) HER2/NEU negative patients and 3(5.7\%) HER2/NEU positive patients, in high KI67 patients' group $>20 \%$ showed 39(62.9\%) HER2/NEU negative patients and 23(37.1\%) HER2/NEU positive patients. Correlation analysis revealed high statistically significance between KI67 and HER2/NEU status $(\mathrm{P}<0.001)$. That is to say KI-67expressing breast cancers were frequently associated with HER2/NEU expressing tumors (Figure 6). 


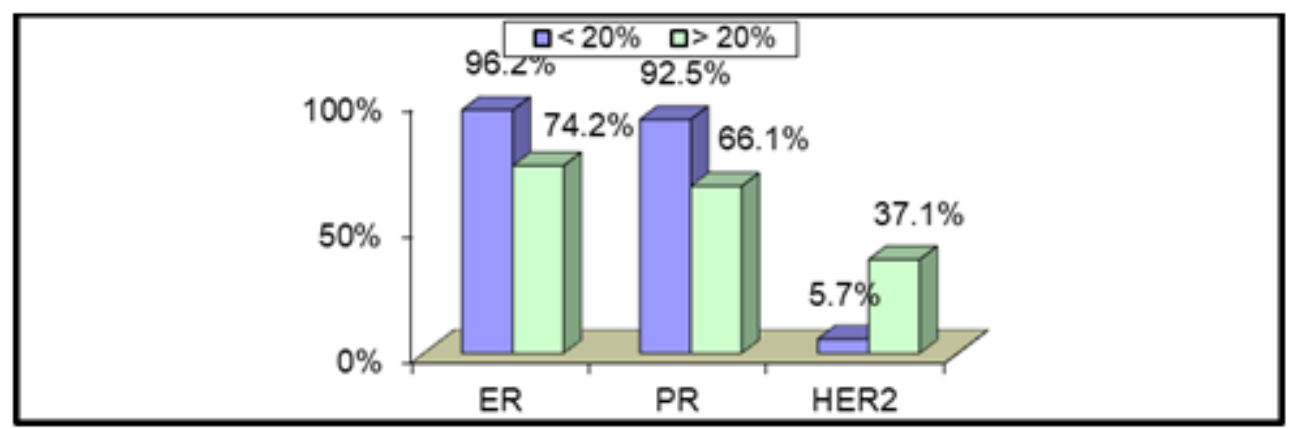

Figure (6): Relation between KI-67 percentage and hormonal status and HER2/NEU of our patients

Ratio of KI-67 and its relation with age, menopausal status, family history, type of surgery, tumor size, histological types and grade showed no significance association between KI-67 and previous parameters on the other hand, Relation between KI-67 and (ER, PR and HER2neu) showed high significance associations between KI-67 and previous parameters, and no significance association between KI-67 and number of metastatic axillary lymph nodes (Table 1).

Table (1): Association between KI-67 and all parameters in our patients

\begin{tabular}{|c|c|c|c|c|}
\hline \multirow{2}{*}{\multicolumn{2}{|c|}{$\begin{array}{ll}\text { Parameters } & \text { Association }\end{array}$}} & \multirow{2}{*}{$\begin{array}{l}<20 \% \\
\text { No. } \%\end{array}$} & \multirow{2}{*}{$\begin{array}{l}>20 \% \\
\text { No. } \%\end{array}$} & \multirow[b]{2}{*}{ P-value } \\
\hline & & & & \\
\hline \multirow{2}{*}{ Age } & Mean \pm SD & $46.58 \pm 9.01$ & $44.40 \pm 7.96$ & \multirow{2}{*}{0.171} \\
\hline & Range & $31-76$ & $30-63$ & \\
\hline \multirow{2}{*}{ Menopause } & Pre menopause & $27(50.9 \%)$ & $34(54.8 \%)$ & \multirow{2}{*}{0.677} \\
\hline & Post menopause & $26(49.1 \%)$ & $28(45.2 \%)$ & \\
\hline \multirow{2}{*}{ MRM } & No & $22(41.5 \%)$ & $24(38.7 \%)$ & \multirow{2}{*}{0.760} \\
\hline & Yes & $31(58.5 \%)$ & $38(61.3 \%)$ & \\
\hline \multirow{2}{*}{$\mathrm{BCS}$} & No & $31(58.5 \%)$ & $38(61.3 \%)$ & \multirow{2}{*}{0.760} \\
\hline & Yes & $22(41.5 \%)$ & $24(38.7 \%)$ & \\
\hline \multirow{5}{*}{ T stage } & TIS & $2(3.8 \%)$ & $0(0.0 \%)$ & \multirow{5}{*}{0.382} \\
\hline & $\mathrm{T} 1$ & $8(15.1 \%)$ & $7(11.3 \%)$ & \\
\hline & $\mathrm{T} 2$ & $29(54.7 \%)$ & $38(61.3 \%)$ & \\
\hline & T3 & $9(17.0 \%)$ & $14(22.6 \%)$ & \\
\hline & T4 & $5(9.4 \%)$ & $3(4.8 \%)$ & \\
\hline \multirow{6}{*}{ Histology } & IDC & $47(88.7 \%)$ & $56(90.3 \%)$ & \multirow{6}{*}{0.534} \\
\hline & ILC & $3(5.7 \%)$ & $3(4.8 \%)$ & \\
\hline & Mixed & $0(0.0 \%)$ & $1(1.6 \%)$ & \\
\hline & Mucinus & $1(1.9 \%)$ & $1(1.6 \%)$ & \\
\hline & DCIS & $2(3.8 \%)$ & $0(0.0 \%)$ & \\
\hline & Medullary carcinoma & $0(0.0 \%)$ & $1(1.6 \%)$ & \\
\hline \multirow{3}{*}{ Grade } & 1 & $0(0.0 \%)$ & $1(1.6 \%)$ & \multirow{3}{*}{0.115} \\
\hline & 2 & $49(92.5 \%)$ & $49(79.0 \%)$ & \\
\hline & 3 & $4(7.5 \%)$ & $12(19.4 \%)$ & \\
\hline \multirow{2}{*}{ ER } & Negative & $2(3.8 \%)$ & $16(25.8 \%)$ & \multirow{2}{*}{$<0.001$} \\
\hline & Positive & $51(96.2 \%)$ & $46(74.2 \%)$ & \\
\hline \multirow{2}{*}{ PR } & Negative & $4(7.5 \%)$ & $21(33.9 \%)$ & \multirow{2}{*}{$<0.001$} \\
\hline & Positive & $49(92.5 \%)$ & $41(66.1 \%)$ & \\
\hline
\end{tabular}


CUTOFF VALUE OF KI-67 BIOMARKER AS PROGNOSTIC MARKER..

\begin{tabular}{|l|l|c|c|c|}
\hline \multirow{2}{*}{ HER2 } & Negative & $50(94.3 \%)$ & $39(62.9 \%)$ & \multirow{2}{*}{$<0.001$} \\
\cline { 2 - 4 } & Positive & $3(5.7 \%)$ & $23(37.1 \%)$ & \\
\hline \multirow{2}{*}{ Dissected LN } & Median (IQR) & $17(13-20)$ & $18(15-22)$ & \multirow{2}{*}{0.091} \\
\cline { 2 - 4 } & Range & $2-36$ & $5-30$ & \\
\hline \multirow{2}{*}{ Positive LN } & Median (IQR) & $2(0-5)$ & $2(0-6)$ & \multirow{2}{*}{0.440} \\
\cline { 2 - 4 } & Range & $0-25$ & $0-29$ & \\
\hline \multirow{4}{*}{ N stage } & No & $18(34.0 \%)$ & $17(27.4 \%)$ & \multirow{3}{*}{0.824} \\
\cline { 2 - 4 } & N1 & $17(32.1 \%)$ & $20(32.3 \%)$ & \\
\cline { 2 - 4 } & N2 & $12(22.6 \%)$ & $15(24.2 \%)$ & \\
\cline { 2 - 4 } & N3 & $6(11.3 \%)$ & $10(16.1 \%)$ & \\
\hline
\end{tabular}

Disease recurrence was reported in $13(21.0 \%)$ patients with high KI-67 compared with only $4(7.5 \%)$ patients with low KI-67, so the effect of KI-67 expression was statistically significant $(\mathrm{P}=0.043)$ saying that high KI-67 expressing tumors are more liable for disease progression.

Among the progressed patients with high KI-67 expression $>20 \%$ there were $6(9.7 \%)$ patients with bone metastasis, $3(4.8 \%)$ patients with liver metastasis, $2(3.2 \%)$ patients with lung metastasis,
$2(3.2 \%)$ patients with local recurrence and $0 .(0.0 \%)$ patients in brain metastasis, compared with low KI-67 expression $<20 \%$ there were $1(1.9 \%)$ patients with bone metastasis, $1(1.9 \%)$ patients with liver metastasis, $2(3.8 \%)$ patients with lung metastasis, $0(0.0 \%)$ patients with local recurrence and $1(1.9 \%)$ patients with brain metastasis. Correlation analysis revealed no statistically significance between KI-67 expression and site of metastasis $(\mathrm{P}=0.227)$ (Table 2$)$.

Table (2): Associations between KI-67 and patient's outcome

\begin{tabular}{|c|c|c|c|c|}
\hline \multirow{2}{*}{\multicolumn{2}{|c|}{$\begin{array}{ll}\text { Parameters } & \text { Associations }\end{array}$}} & \multirow{2}{*}{$\begin{array}{l}\mathbf{2 0 \%} \\
\text { No. } \%\end{array}$} & \multirow{2}{*}{$\begin{array}{l}>20 \% \\
\text { No. } \%\end{array}$} & \multirow{2}{*}{ P-value } \\
\hline & & & & \\
\hline Relance & No & $49(92.5 \%)$ & $49(79.0 \%)$ & \\
\hline Relapse & Yes & $4(7.5 \%)$ & $13(21.0 \%)$ & 0.043 \\
\hline & No & $48(90.6 \%)$ & $49(79.0 \%)$ & \\
\hline & Lung & $2(3.8 \%)$ & $2(3.2 \%)$ & \\
\hline & Liver & $1(1.9 \%)$ & $3(4.8 \%)$ & \\
\hline Site & Bone & $1(1.9 \%)$ & $6(9.7 \%)$ & 0.227 \\
\hline & Brain & $1(1.9 \%)$ & $0(0.0 \%)$ & \\
\hline & Local & $0(0.0 \%)$ & $2(3.2 \%)$ & \\
\hline & Alive & $31(58.5 \%)$ & $33(53.2 \%)$ & \\
\hline Status & Died & $3(5.7 \%)$ & $6(9.7 \%)$ & 0.689 \\
\hline & Lost FU & $19(35.8 \%)$ & $23(37.1 \%)$ & \\
\hline
\end{tabular}

As regard the effect of KI-67 expression and overall survival, there are high KI-67 (P=0.390) (Table 3 and no statistically significance for low and Figure 7).

Table (3): Association between KI-67 expression and patients' survival

\begin{tabular}{|c|c|c|c|c|c|c|c|}
\hline \multirow{2}{*}{ KI } & \multirow{2}{*}{ Total N } & \multirow{2}{*}{$\begin{array}{c}\mathrm{N} \text { of } \\
\text { Events }\end{array}$} & \multirow{2}{*}{ Mean } & \multirow{2}{*}{ SE } & \multicolumn{2}{|c|}{$95 \% \mathrm{CI}$} & \multirow[t]{2}{*}{ P-value } \\
\hline & & & & & Lower & Upper & \\
\hline$<20 \%$ & 34 & 3 & 74.054 & 2.808 & 68.551 & 79.558 & \\
\hline$>20 \%$ & 39 & 6 & 67.410 & 3.286 & 60.969 & 73.852 & 0.390 \\
\hline
\end{tabular}




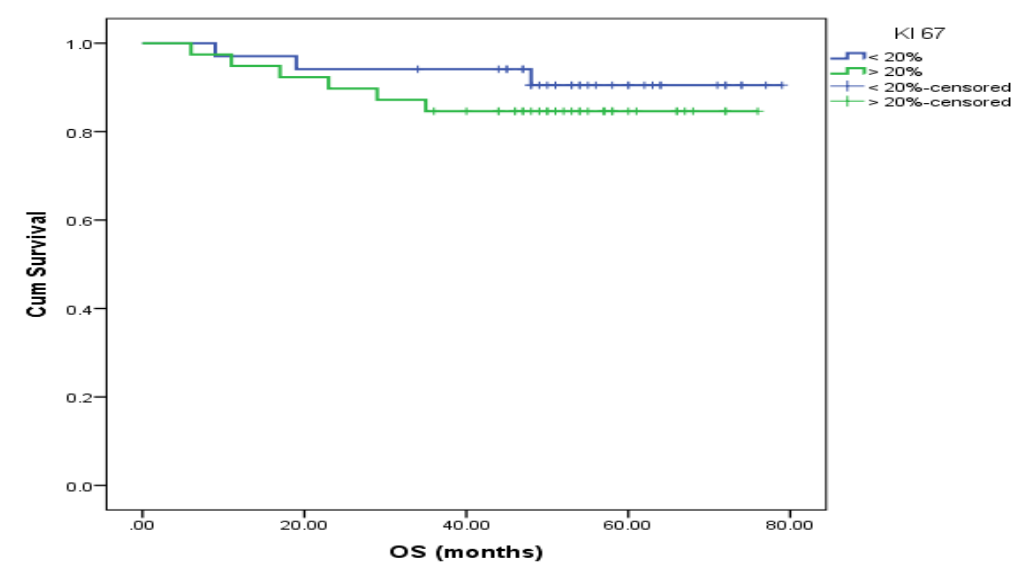

Figure (7): OS Kaplan-Meier curve

As regard the effect of KI-67 expression and patients' survival, we found that KI-67 is statistically significance with disease free survival with $(\mathrm{P}=0.036)$ ensuring its prognostic importance in breast cancer patient (Table 4 and Fig 8).

Table (4): Association between KI-67 expression and DFS

\begin{tabular}{|c|c|c|c|c|c|c|c|}
\hline \multirow{2}{*}{ KI } & \multirow{2}{*}{ Total N } & \multirow{2}{*}{$\begin{array}{c}\text { N of } \\
\text { Events }\end{array}$} & \multirow{2}{*}{ Mean } & \multirow{2}{*}{ SE } & \multicolumn{2}{|c|}{ 95\% CI } & P-value \\
\cline { 6 - 8 } & & 4 & 75.295 & 2.283 & 70.82 & 79.769 & \\
\hline$<20 \%$ & 53 & 43 & 57.431 & 2.86 & 51.825 & 63.038 & 0.036 \\
\hline$>20 \%$ & 62 & 13 &
\end{tabular}

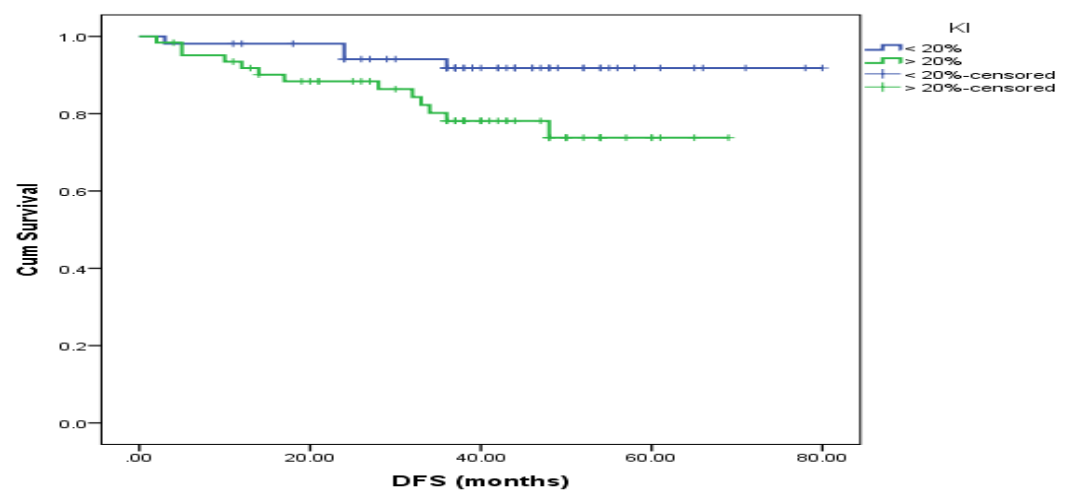

Figure (8): DFS Kaplan-Meier curve

All clinical and histopathological data were tested for their prognostic value in a multivariate analysis for disease free survival. The disease-free survival probabilities were calculated by KaplanMeier Estimates (P-value for log rank test). All parameters were of significant correlation for DFS. The overall survival probabilities calculated by Kaplan-Meier Estimates (P-value for log rank test). All parameters showed non-significant correlation for OS. 


\section{DISCUSSION}

It is well acknowledged that state-ofthe-art treatment of breast cancer is most dependent on optimal assessment of involved prognostic factors. Though in excess of a hundred factors have been reported in the literature, only a few evidently succeeded to make their way into routine practice as established prognostic tools (Seema et al., 2017).

In this study, our aim was to clarify the association between KI-67 expression and other clinical and pathological parameters and to show its effect on patients' outcome. We compared KI-67 staining frequency according to the various prognostic factors. KI-67 positivity was more frequently found in patients with high grade tumors, hormonal negative and HER2/NEU positive tumors, suggesting that KI-67 was involved in aggressive breast cancer. Moreover, patients with positive KI-67 >20\% showed significantly poorer prognosis than those with negative KI-67<20\%.

We found no association between KI67 expression and age nor with menopausal status. The relationship between KI-67 expression with age and menopausal status has been previously explored in number of studies. The prognostic factor KI-67 was statistically significant with age (Nishimiya et al., 2014).

We found no association between KI67 expression and tumor size. The relationship between KI-67expression with tumor size has been previously explored in number of studies. In one of this study done on BC patients, there were no correlations between KI-67 with tumor size (Mirmalek et al., 2016).
We found no association between KI67 expression and histological type. The relationship between KI-67 expression and histological type has been explored in only a small number of studies.

We found no significance between KI67 and tumor grade. On the contrary, a study found a significance correlation between KI-67 and grade (Mirmalek et al., 2016).

We found that KI-67 expression had no significance with positive lymph nodes metastasis. Another study also found no correlation between nodal metastasis and KI-67 expression (Cheng-Har et al., 2016). On the contrary, a study was done on $\mathrm{BC}$ and found a significant association between KI-67 and lymph nodes metastasis (Mirmalek et al., 2016).

We found a high significance relation between KI-67 and hormonal receptors status. A study found a significant correlation between KI-67 and ER, PR status which concluded that KI-67 in breast malignancies has proved its prognostic value, particularly in subgrouping HR-positive breast cancer (Krishnanz, 2015). Another study failed to reveal any significance between KI-67 and hormone receptors. The difference may be due to different cut-of as they used (Awadeikarim et al., 2012).

In our study, we found that KI-67 expressing tumors were strongly associated with Her-2/neu. This associated was evaluated in many studies. A study found a strong association with Her-2/neu status (Saroona et al., 2013). On the contrary, a study failed to reveal any significant association of KI-67 with Her$2 /$ neu this difference may be due to 
different cut off values (Awadeikarim et al., 2012).

We were able to prove a significant correlation between KI-67expression and earlier onset of recurrence and proved a significant correlation between KI-67 expressions and DFS, that high KI-67 expressing tumors were more liable for disease progression. As regard the association between KI-67 and death rates, there was no significant difference between low and high KI-67 group patients found in our study. A study found also a strong significance between KI-67 and DFS and OS for both. Overall survival was evaluated in 10 years follow up (Nishimiya et al., 2014).

The discrepancy among the results of different studies concerning the correlation of KI-67 with patient and disease characteristics and with recurrence and survival outcomes may originate, from different types of studied female BC samples or sample size population characteristics, different methods for assaying KI-67, differences in scoring method or different cutoff to designate high or low KI-67. Our study may provide insights into a probable predictive value for KI-67 in breast cancer treatment.

\section{CONCLUSION}

Patients with positive KI-67\% showed significantly poorer prognosis than those with negative KI-67\%. This may show that KI-67\% was the most robust independent prognostic factor in multivariate prognostic analysis, despite having very strong correlations with other biomarkers such as hormone receptor status (ER \& PR) and HER2neu.

\section{Competing interests:}

The authors declare that they have no competing interests.

\section{Authors' contributions:}

All authors involved in design, writing, revising the manuscript and approval of final version, involved in conception design, data collection, literature review, writing the manuscript, and approval of final version, in design, data collection, literature review, writing, revising the manuscript, and approval of final version of manuscript. Additionally, all authors have read and approved the final manuscript.

\section{REFERENCES}

1. Awadeikarim KD, Costantini RM, Osman I and Barberis MC (2012): Ki-67 Labelling Index in Primary Invasive Breast Cancer from Sudanese patients; A Pilot study. Path.; 14(3): 100-17.

2. Brandt J, Garne, J, Tengrup I and Manjer J (2017): Age at diagnosis in relation to Survival following breast cancer: a cohort study. World Journal of surgical Oncology, 13(1):33-41.

3. Cheng-Har Y, Bhoo-Pathy N, Daniel JM, Foo YC, Mohamed AK and Abdullah MM (2016): Roles of ki67 in breast cancer important for Management? Asian Pac J Cancer Prev.,17 (3):1077-1082.

4. Giuliano, A. E., Connolly, J. L., Edge, S. B., Mittendorf, E. A., Rugo, H. S., Solin, L. J., ... \& Hortobagyi, G. N. (2017): Breast cancer-major changes in the American Joint Committee on Cancer eighth edition cancer staging manual. CA: a cancer journal for clinicians, 67(4), 290-303.

5. Gonzalez- Angulo AM, Litton JK, Broglio KR, Meric- Bernstam F, Rakkhit $R$ and Cardoso F (2011): High risk of recurrence for patients with breast cancer who have human epidermal growth factor receptor 2- 
positive, node-negative tumors $1 \mathrm{~cm}$ or smaller J. Clin. Oncol., 27(34); 5700-6.

6. Jemal, A., Bray, F., Center, M. M., Ferlay, J., Ward, E., \& Forman, D. (2011): Global cancer statistics. CA: a cancer journal for clinicians, 61(2), 69-90.

7. Kartinen M (2014): Breast cancer in the eighteenth century. Social History of Medicine, 27(3):598-599.

8. Mirmalek S. A, Ghorbani M, Boushehrinejad AG, Salehi M, Alireza S, Salimi-Tabatebasee $\mathrm{SA}$ and Aryan $\mathrm{H}$ (2016): Correlation of ki67 expression with hormone receptors, Human epidermal growth factor receptor-2 status, P53 Mutation and clinicopathological charecterstics in pathologic specimens of breast cancer patients.Galen Med J., 5(2):27-43.

9. Nishimiya H, Oshimasa Y K, Yamashita K, Minatani N, Kikuchi $M$ and Ema A, (2014): Prognostic significance of Ki-67 in Chemotherapy-naïve Breast Cancer Patients with 10-year Follow-up. Anti-cancer Researche., 34; 259-268.

10. Pinto AC and De Azambuja E (2011): Improving quality of life after breast cancer: dealing with symptoms. Maturitas, 70(4):343-48.
11. Saroona H, Atif A.H, Amna K, Muhammed A.K, Shafaq $M$ and Babar $M$ (2013): KI67 index in breast cancer: Correlation with other prognostic markers and potential in Pakistani patints. Asian Pacific Journal of Cancer Prevention, 1(7):4353-4358.

12. Schmidt M, Gehrmann M, Hengstler JG and Koelbl H. (2012): new prognosis and predictive factors in breast cancer.Minerva Ginecol., 62(6):599-611.

13. Seema K, Anil K.B, Murali G.M, Shailender G.N and Rama R.M (2017): Synergistic effects of coralyne and paclitaxel on cell migration and proliferation of breast cancer cell lines. Biomedicine and Pharmacotherapy, 91:436-445.

14. Taneja P, Maglic D and Kai F (2014): Classical and Novel Prognostic Markers for breast cancer and their clinical significance. Clin Med Insights Oncol., 4:15-34. 
القيمة الحدية للمعامل البيولوجى KI-67 للتنبوء بالتطور

المرضى لسرطان الثذى عند السيدات

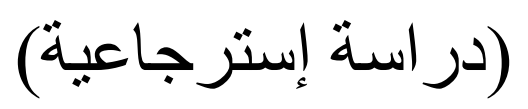

نبيل دسوقي البحر، هشام عباس العبادي، أحمد يسري العجماوي

قسم علاج الاورام والطب النووي، كلية الطب، جامعة الازهر

E-mail: nabil.elbahr3@gmail.com

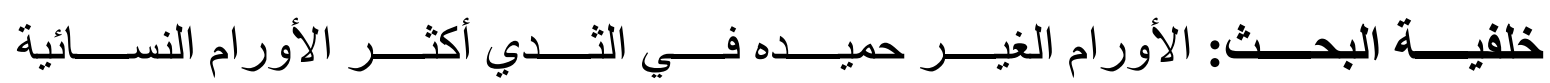

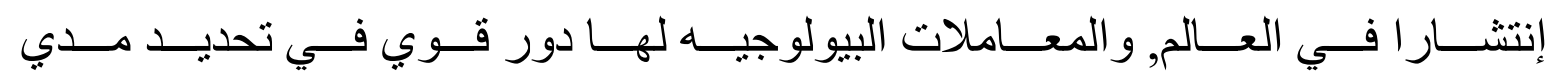
تطور المرض ويعد أهمها هو المعامل البيولوجي KI-67.

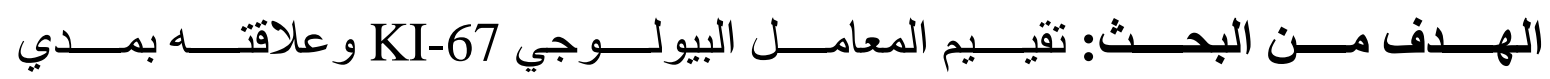

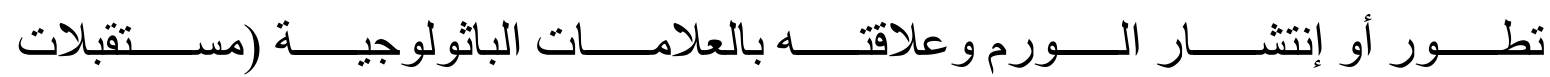

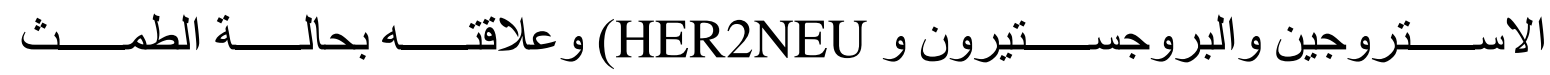
و العمر ونوع وحجم الورم ومر احل الورم المتعددة.

المريضـــات وطــــرق البحـــث: تضـــمن البحــــ115 مريضـــات بالغـــات عــانين

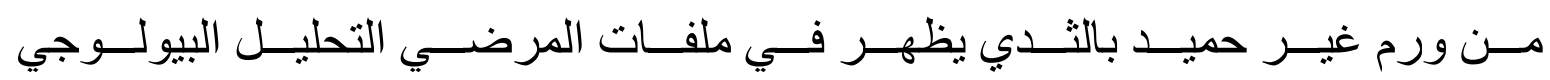

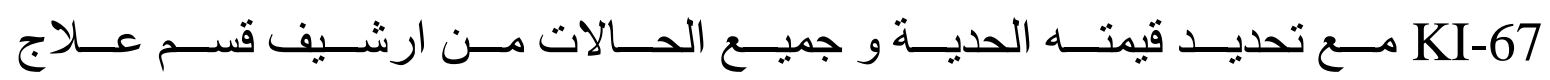

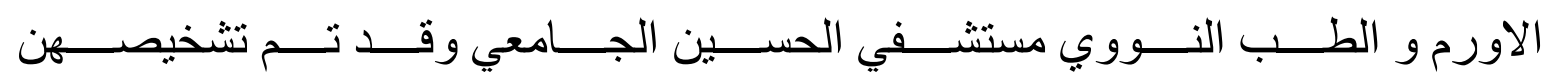
وعلاجهن في الفترة من يناير 2014 الي ديسمبر 2017.

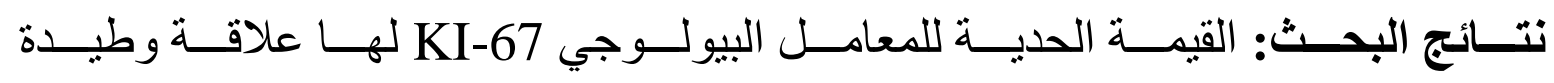

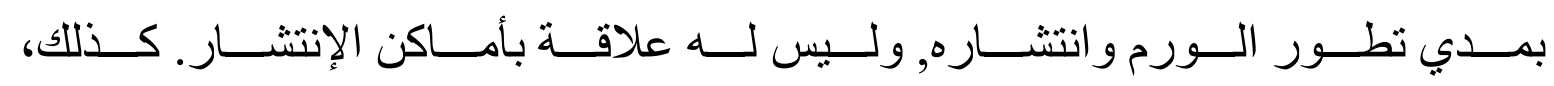

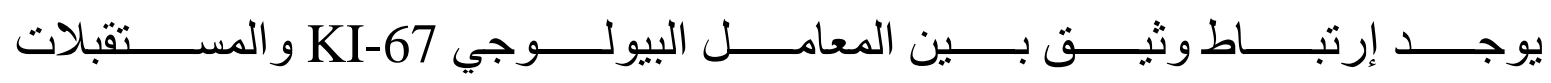

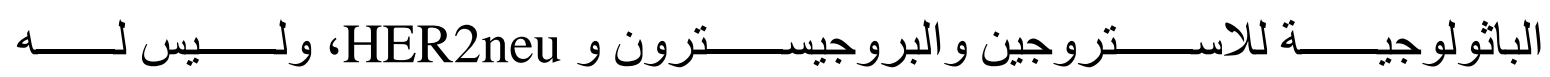


CUTOFF VALUE OF KI-67 BIOMARKER AS PROGNOSTIC MARKER... 561

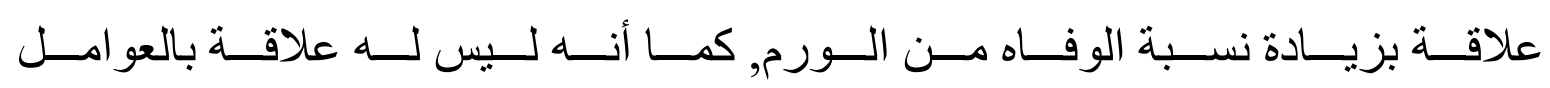
الأخري مثل حجم الورم ودرجة و أنواع الخلايا الهيستولوجيه بالورم.

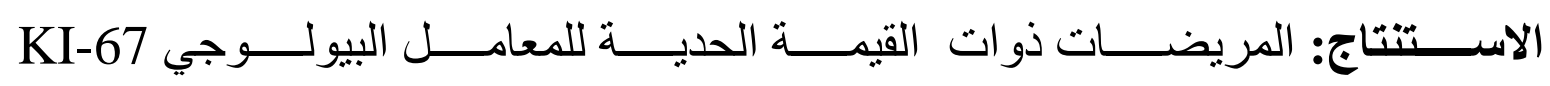

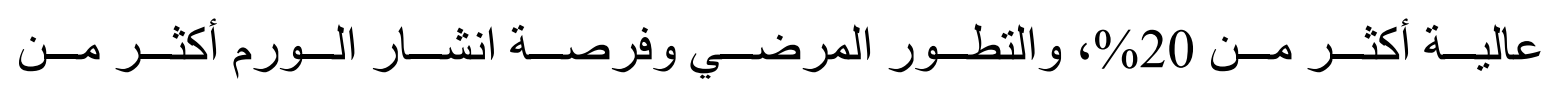

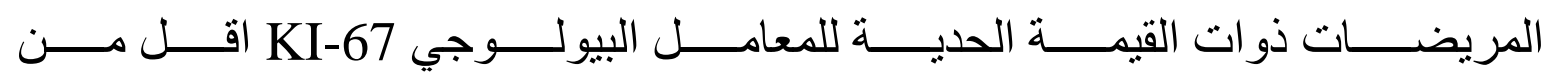

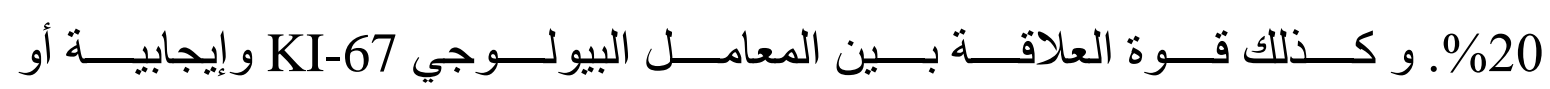

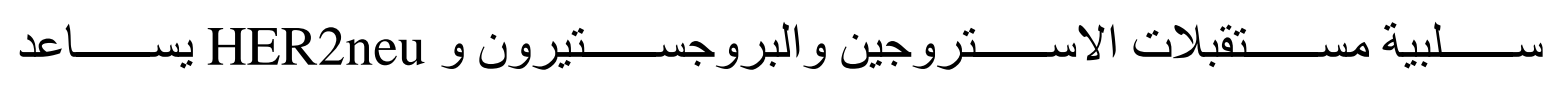
علي تحديد وتقييم العلاج المختار مع توقع مدي الاستجابة للعلاج.

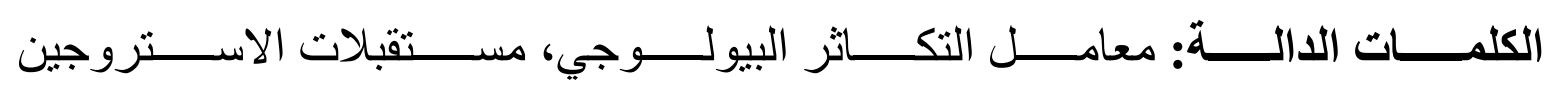

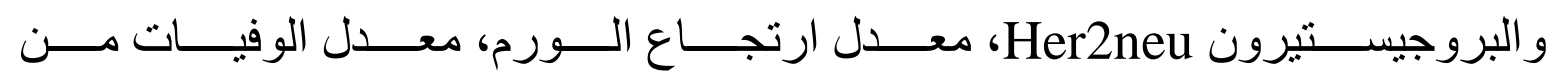

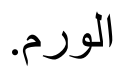

